\title{
PACTO NACIONAL PELA ALFABETIZAÇÃO NA IDADE CERTA: O OLHAR DE PROFESSORES QUE ENSINAM MATEMÁTICA
}

\author{
RIGHT-AGE NATIONAL LITERACY PACT: LOOK OF TEACHERS \\ TEACHING MATHEMATICS
}

\author{
Fabiana Fiorezi de Marco \\ Universidade Federal de Uberlândia - UFU \\ fabiana.marco@ufu.br \\ Lúcia Eneida de Sousa Alves Simão \\ Professora da Rede Municipal de Ensino de Uberlândia \\ lucia.eneida@hotmail.com
}

\begin{abstract}
Resumo
Este artigo é parte de uma pesquisa realizada com a participação de um grupo de professores da rede pública municipal da cidade de Uberlândia, MG e tem como objetivo compreender o contexto de formação utilizado pelo curso PNAIC, os principais recursos metodológicos e a linguagem utilizada nos Cadernos de Formação, bem como revelar as memórias da vida estudantil das professoras participantes e suas influências em suas vidas profissionais. $\mathrm{O}$ grupo de participantes foi constituído por cinco professoras e para a produção do material de análise, foram utilizados: questionário; registros escritos das participantes; sessões reflexivas; caderno de anotações das participantes; e, notas de campo da pesquisadora. As Sessões Reflexivas se constituíram como método de pesquisa que vai além da observação. A aproximação com os conhecimentos matemáticos, concepções e práticas pedagógicas das professoras, bem como o diálogo e o pensar junto justificam nossa escolha por esse procedimento, visto que ele amplia e possibilita a reflexão das participantes da pesquisa. As vivências compartilhadas durante as sessões reflexivas realizadas trouxeram expectativas e necessidades formativas das professoras participantes deste estudo. As informações obtidas deixam evidenciadas a importância de um trabalho de formação continuada que valorize a colaboração e o envolvimento dos profissionais em busca de novas percepções, e também a necessidade da continuidade de oferta de estudos para docentes.
\end{abstract}

Palavras-chave: Ensino de Matemática. Formação continuada de professores. Professores que ensinam Matemática, Pacto Nacional pela Alfabetização na Idade Certa.

\begin{abstract}
This article is part of a research conducted with the participation of a group of teachers from the municipal public network of the city of Uberlândia/MG and aims to understand how teachers who attended the continuing education of PNAIC in 2014 understood and understood this training. The group of participants consisted of five teachers and for the production of analysis material, a questionnaire was used; written records of participants; reflective sessions; notebook the participants; and field notes from the researcher. The Reflective Sessions were constituted as a research method that goes beyond observation. The approach with the mathematical knowledge, conceptions and pedagogical practices
\end{abstract}


of teachers, as well as dialogue and thinking together justify our choice for this procedure, since it broadens and enables the reflection of the research participants. The experiences shared during the reflective sessions held brought expectations and formative needs of the teachers participating in this study. The information obtained highlights the importance of a continuing education work that values the collaboration and involvement of professionals in search of new perceptions, and also the need to continue offering studies for teachers.

Keywords: Mathematics Teaching. Continuing teacher training. Teachers Teaching Mathematics. Right-Age National Literacy Pact.

\section{INTRODUÇÃO}

O cenário atual da Educação brasileira nos leva a pensar os motivos pelos quais a disciplina de Matemática não tem apresentado resultados satisfatórios em termos de desempenho dos alunos. Esse fato se comprova pelas avaliações internas e externas das escolas e divulgadas pelos índices dos governos federal, estadual e municipal. Em seus estudos, Mundim (2015) confirma que os dados referentes aos saberes matemáticos dos alunos que cursam os primeiros anos do Ensino Fundamental não conseguem alcançar nem $50 \%$ da escala estabelecida pelo Instituto Nacional de Estudos e Pesquisas Educacionais Anísio Teixeira (INEP). A autora esclarece que:

[...] no ano de 2005 , os resultados chegaram a $42 \%$ gerando muitas preocupações a respeito da aprendizagem dos alunos. No ano de 2007 os níveis de desempenho chegaram a $44 \%$, demonstrando que a melhoria foi ínfima. Em 2009 os alunos alcançaram 47\% nos resultados. Já no ano 2011, o índice foi de 48\% (MUNDIM, 2015, p. 30).

Mundim (2015) também destaca que além de baixos, os resultados não subiram nem $4 \%$ de um ano para o outro. Outro fator preocupante que ela realça são os índices do Sistema Mineiro de Avaliação da Educação Básica (SIMAVE) que também não chegam a 50\%, como é estabelecido pela escala proposta pelo Programa de Avaliação da Rede Pública de Educação Básica (PROEB). Assim:

[...] analisando esses resultados, verifica-se que do ano de 2008 a 2012 estes não subiram nem $2 \%$ a cada ano, no aumento do desempenho dos alunos no ensino. Essa realidade, mais uma vez, vem sendo motivo de preocupações e busca de soluções. No ano de 2008, alcançou-se 42,5\%. No ano de 2009 , o índice gerado foi de $44 \%$. Em 2010, os resultados chegaram a 45\%. Já em 2011, encontra-se em 46\%. E em 2012, os resultados foram de 46,5\% (MUNDIM, 2015, p.32).

De acordo com os Parâmetros Curriculares Nacionais (PCN), "Além dos índices que indicam o baixo desempenho dos alunos na área de Matemática em testes de rendimento, também são muitas as evidências que mostram que ela funciona como filtro para selecionar alunos que concluem, ou não, o Ensino Fundamental” (BRASIL, 1997, p. 
24). Esses mesmos documentos entendem que "[...] parte dos problemas referentes ao ensino dessa disciplina estão relacionados ao processo de formação do magistério, tanto em relação à formação inicial como à formação continuada" (BRASIL, 1997, p. 24). Esse quadro traz certa angústia para os professores dos anos iniciais que ensinam essa disciplina. Nesse sentido, temos dois grandes problemas que se inter-relacionam: por um lado, as dificuldades que os alunos têm em relação à disciplina de Matemática que contribui para essa situação de insucesso escolar e, por outro, a formação inicial e continuada de professores que ensinam Matemática, em que temos visto tentativas de algumas políticas públicas (PNAIC, Observatório da Educação, PIBID etc), embora os resultados mostrem uma boa contribuição de tal ato (SIMÃO, 2019). No entanto, diante do tamanho do problema, tais políticas de formação de professores deveriam ser aperfeiçoadas e não extintas. Esse problema parece ser agravado no processo de escolarização dos anos iniciais do Ensino Fundamental, uma vez que a Matemática é uma disciplina ministrada por professores que nem sempre se sentem confortáveis diante dela.

Sendo a formação continuada de professores um dos grandes problemas da Educação, a expectativa é que, no convívio com a reflexão das práticas pedagógicas baseadas nas propostas desencadeadas pela formação do PNAIC, as experiências, os saberes docentes e os conhecimentos matemáticos sejam reconstruídos em um processo dialógico que permitam a percepção da importância dele e da permanência das mudanças que o mesmo provocou.

O estudo ora apresentado, recorte de uma pesquisa de mestrado, foi realizado com cinco professoras da rede municipal de ensino do Ensino Fundamental I, na cidade de Uberlândia/MG, no ano de 2018.

Destarte, esse artigo tem como objetivo compreender o contexto de formação utilizado pelo curso PNAIC, os principais recursos metodológicos e a linguagem utilizada nos Cadernos de Formação, bem como revelar as memórias da vida estudantil das professoras participantes e suas influências em suas vidas profissionais. Para a organização do texto, explicitamos inicialmente os pressupostos teóricos que nos orientaram; a seguir, com o intuito de desvelar nosso objeto de investigação, qual seja, a percepção de professoras sobre a formação continuada vivenciada no PNAIC no ano de 2014, analisamos depoimentos realizados em sessões reflexivas e registros escritos das participantes; e, por fim, concluímos com algumas considerações sobre o estudo. 


\section{A FORMAÇÃO DE PROFESSORES DOS ANOS INICIAIS E O PNAIC}

A formação inicial dos professores dos primeiros anos do Ensino Fundamental tem sido motivo de muitos estudos e preocupações e, em especial, a Educação Matemática. O professor em exercício, advindo de uma formação inicial, necessita “[...] ter uma profunda compreensão da Matemática que não se limite a um conhecimento tácito do tipo saber fazer, mas se traduza num conhecimento explícito" (SERRAZINA, 2012, p.282).

Consideramos importante que a formação do professor se efetive em uma base de conhecimento em sua formação inicial, no curso de Graduação, garantindo uma formação geral da área disciplinar e pedagógica. Acreditamos, ainda, ser interessante a atualização constante por meio de participação em grupos de estudos ou até mesmo a oferta de cursos contínuos de formação que lhes assegurem uma reelaboração contínua dos conhecimentos adquiridos que essas situações possam permitir.

Especificamente, no ano de 2014, foi oferecido a professores em exercício o curso de formação continuada Pacto Nacional pela Alfabetização na Idade Certa (PNAIC) com o tema Alfabetização Matemática, foco dessa pesquisa que se debruça tão somente neste ano de atuação pelo interesse na área de conhecimento já mencionada.

Assim, este texto é produto de uma reflexão sobre o PNAIC-2014, a partir do olhar de professoras alfabetizadoras acerca das implicações didático-pedagógicas de tal curso para a sua prática diária, apontando as contribuições, reflexões e resultados do Programa com base em suas experiências, relatando opiniões, facilidades e dificuldades encontradas no processo.

Consideramos que, os professores, peças fundamentais no processo de transformação social, estão em contato direto com a Educação, cada dia mais complexa e a convivência com as incertezas e com as mudanças rápidas perpassadas pela sociedade. Dessa forma, o compartilhamento de experiências pedagógicas e metodológicas contribui para o desenvolvimento profissional e para o processo formativo dos professores, fato este confirmado por Tardif (2014, p.11) quando alega que:

[...] o saber dos professores é o saber deles e está relacionado com a pessoa e com a identidade deles, com a sua experiência de vida e com a sua história profissional, com as suas relações com os alunos em sala de aula e com os outros atores escolares na escola, etc. Por isso, é necessário estudá-lo relacionando-o com esses outros elementos constitutivos do trabalho docente. 
Seria interessante que, cada vez mais, professores se tornassem pesquisadores e estudiosos em busca de conhecimentos para tentarem solucionar problemas do dia a dia. Entretanto, vários são os fatores que influenciam a pesquisa na Educação e entre eles, destacamos: a falta de tempo e incompatibilidade de horários para estudos; necessidades financeiras que impõem carga excessiva de trabalho; desinteresse e desestímulo frente a situações cotidianas; falta de políticas públicas mais efetivas; despreparo dos ministrantes e professores em geral; e tantos outros. "Entretanto, essa discussão torna-se importante à medida que ajuda a explicitar as direções possíveis de uma investigação e suas diferentes consequências" (GIL, 2008, p. 35).

Para o estudo e a análise do material que constitui o PNAIC, consultamos os documentos oficiais do Governo, as portarias e os materiais disponíveis no site que instituiu, regulamentou e normatizou o Programa. Utilizamos também como fonte de pesquisa e de orientação os Cadernos de Apresentação e Organização do Trabalho Pedagógico do ano de 2014 e os Cadernos de Formação de Professores do PNAIC do referido ano.

O documento "Elementos Conceituais e Metodológicos para a definição dos Direitos de Aprendizagem", que formalmente fundamenta a elaboração das propostas do curso oferecido pelo PNAIC, foi construído em uma urgência histórica de que o Brasil precisa educar com qualidade social todos os seus cidadãos, porque "[...] esta tarefa tem na escola pública seu principal e mais amplo espaço de construção" (BRASIL, 2012b, p. 6). Sendo assim:

O PNAIC é um acordo formal assumido pelo Governo Federal, pelos estados, pelos municípios e por entidades, para firmar o compromisso de alfabetizar crianças até, no máximo, oito anos de idade, ao final do ciclo de alfabetização (BRASIL, 2012a, p. 5).

Além de assegurar que todas as crianças estejam alfabetizadas em Língua Portuguesa e em Matemática até os oito anos de idade, o PNAIC tem por objetivo diminuir a distorção idade série na Educação Básica, melhorar o Índice de Desenvolvimento da Educação Básica - IDEB, construir propostas para a definição dos Direitos de Aprendizagem e desenvolvimento das crianças no Ciclo de Alfabetização e, ainda, contribuir para o aperfeiçoamento da formação de professores alfabetizadores. Assim, é um Programa governamental, implementado em 2013, como uma estratégia de formação continuada de professores alfabetizadores das séries iniciais do Ensino Fundamental que atuam na rede pública de ensino. 
Isto posto, procuramos tecer considerações que sinalizam a problemática dessa pesquisa com seus objetivos, motivos e relevância. Sabemos, também, que "A relevância social de um problema está relacionada indubitavelmente aos valores de quem a julga" (GIL, 2008, p. 35).

Consideramos de fundamental importância que o professor, ao ensinar Matemática, tenha conhecimentos específicos sobre a disciplina e ainda saiba organizar sistematicamente sua prática docente, de maneira a atender tanto às exigências legais quanto às reais necessidades dos alunos. Concordando com essa ideia, no Caderno do Pacto Nacional pela Alfabetização na Idade Certa de Alfabetização Matemática (PNAIC), os autores ressaltam que: "O professor alfabetizador deve ser tratado como um profissional em constante formação, não só na área de linguagem, mas em todas que façam parte do ciclo de alfabetização" (BRASIL, 2014a, p. 10).

A formação continuada de professores que ensinam Matemática justifica-se pela importância de se criar uma relação dialógica entre professores e sala de aula para o saber pensar matemático, estabelecendo uma melhor comunicação e interação com professores e alunos. Um ambiente de aprendizagem pautado no diálogo, nas interações e na produção de sentidos e significados, um processo do qual quem ensina e quem aprende são partes (MARCO; MOURA, 2016).

Tomamos como protagonistas cinco professoras alfabetizadoras que ensinam Matemática em uma escola pública municipal da cidade de Uberlândia e temos como fonte de informações suas produções: Questionário; diálogos sobre lembranças do curso PNAIC; Registros Escritos; Caderno de Anotações com reflexões sobre a prática pedagógica; Sessões Reflexivas vídeogravadas e também Notas de Campo de pesquisadora. Apresentamos, a seguir, o perfil das professoras participantes da pesquisa, colaboradoras do nosso trabalho, caracterizadas por idade, nome, atuação e formação docente nas escolas.

\section{SESSÃO REFLEXIVA}

Após a submissão do projeto de pesquisa ao Comitê de Ética em Pesquisa com Seres Humanos na Universidade Federal de Uberlândia (CEP/UFU) junto à Plataforma Brasil, aprovado por meio do Parecer n. 2.910.243, foi realizado um levantamento junto às escolas sobre docentes que participaram da formação continuada do PNAIC-2014, 
encaminhamos o convite para participar da pesquisa aos professores que obtivemos o contato.

O grupo de professoras participantes foi selecionado a partir dos seguintes critérios: ser efetivo na rede municipal de Uberlândia; ter experiência mínima de cinco anos na docência nos primeiros anos do Ensino Fundamental; ter participado da formação continuada do PNAIC-2014; e, ter disponibilidade para participar da pesquisa.

Do retorno obtido, cinco professoras atendiam aos critérios estabelecidos. O fato de haver um grupo menor de participantes permitiria uma análise mais detalhada das informações, na tentativa de compreender melhor cada detalhe do nosso objeto de pesquisa. Ressaltamos que foi preservada a identidade das professoras participantes ao utilizarmos nomes fictícios.

Como instrumentos de pesquisa utilizamos: i. Questionário; ii. Registros Escritos; iii. Sessões Reflexivas; iv. Caderno de Anotações; e v. Notas de Campo da pesquisadora. As Sessões Reflexivas (IBIAPINA, 2008), foram utilizadas "como um método de pesquisa que vai além da observação, e leva o pesquisador a centrar sua análise em longas conversas, em pequenos grupos, a fim de oportunizar trocas de opiniões sobre determinada questão" (LOPES, et al., 2019). A aproximação com os conhecimentos matemáticos, concepções e práticas pedagógicas das professoras, bem como o diálogo e o pensar junto justificam nossa escolha por esse procedimento, visto que ele amplia e possibilita a reflexão das participantes da pesquisa.

As sessões reflexivas são espaços criados para debater e analisar a prática docente, recursos vitais para o estabelecimento da relação teoria-prática e o ponto de partida para a reflexão crítica sobre os princípios teóricos que subjazem as opções pedagógicas e didáticas feitas no percurso da atividade docente. São momentos de diálogos em que cada participante descobre tanto significados pessoais quanto os já construídos coletivamente pela categoria (IBIAPINA, 2008).

\section{A PRODUÇÃO DAS INFORMAÇÕES}

Para este artigo, selecionamos depoimentos das professoras manifestados durante as sessões reflexivas, nos quais os questionamentos realizados favoreceram a reflexão sobre suas práticas e as auxiliaram a romperem com as estruturas tradicionais visando uma prática colaborativa. $\mathrm{O}$ eixo de análise que ora apresentamos aborda o contexto de formação utilizado pelo curso PNAIC, os principais recursos metodológicos e a 
linguagem utilizada nos Cadernos de Formação, e as memórias da vida estudantil das professoras participantes e suas influências em suas vidas profissionais.

\section{A dinâmica do Curso do Formação do PNAIC Alfabetização Matemática e as memórias de formação da vida escolar das participantes}

Investigar a formação oferecida pelo PNAIC Alfabetização Matemática sob a visão das professoras pesquisadas é que procuramos perceber a dinâmica do curso. Aqui adotamos o conceito de formação utilizado por Imbernón (2004, p. 49), no qual cabe ao professor "[...] descobrir, organizar, fundamentar, revisar e construir a teoria" e, ainda assim, “[...] o profissional de Educação é construtor de conhecimento pedagógico de forma individual e coletiva". Essas ideias de Imbernón (2004) podem ser percebidas na reflexão e nos depoimentos das professoras participantes, pois entendem que a Educação é algo fundamental e de grande relevância social.

Durante as Sessões Reflexivas nos ficou claro que, “[...] os saberes experenciais adquirem também uma certa objetividade em sua relação crítica com os saberes disciplinares, curriculares e da formação profissional" (TARDIF, 2014, p. 53). A possibilidade de participação no PNAIC 2014 foi vista, pelas professoras, como uma oportunidade de aprendizagem, de troca de saberes, um rico momento de reflexão sobre a prática pedagógica e, ainda, uma oportunidade para resolver conflitos internos sobre o ensino e a aprendizagem da Matemática. Os depoimentos das professoras Salete ${ }^{1}$ e Edilene nos dizem um pouco sobre essa participação:

O PNAIC propiciou momentos de trocas de experiências entre os profissionais. Tivemos a oportunidade de refletir sobre nossas práticas em salas de aulas e assim resgatar algumas que vinham sendo esquecidas ao longo do tempo (Professora Salete. Sessão Reflexiva, 09/10/2018).

O curso e a participação nesta pesquisa contribuíram bastante, principalmente na visão da Matemática como uma vilã, dificil de aprender, dificil de ensinar. Gostaria de ter a oportunidade de colocar tudo que foi trabalhado em prática efetivamente, mas para tal seria necessário, mudanças de posturas, salas de aulas menos cheias, materiais que dêem para todos os alunos, entre outros. Mudou minha maneira de pensar, mas gostaria de poder mudar totalmente na realidade (Professora Edilene, Sessão Reflexiva, 09/10/2018).

Entendemos que a inserção em espaços formativos permite a reflexão sobre a própria prática docente de maneira mais crítica e consciente, sabendo-se que quanto

\footnotetext{
${ }^{1}$ Os nomes das participantes são fictícios para preservação de suas identidades.
} 
melhor e mais preparado o profissional, melhor será a qualidade das aulas planejadas e organizadas para que atinja os objetivos propostos. Esse é o motivo pelo qual a grande questão está em entender que o professor é o principal agente transformador da Educação.

Informações obtidas durante a pesquisa nos fazem acreditar que, ao escrever e relatar fatos e experiências, as professoras refletiam sobre suas ações e, assim, repensavam-nas, reconstruíam significados para próximas ações docentes, influenciavam na prática diária e no planejamento de atividades para seus alunos e procuravam melhor atingir os objetivos propostos. Alguns desses aspectos podem ser percebidos nas falas a seguir:

Percebi que o PNAIC foi excelente do ponto de vista teórico, mas que, para ser colocado em prática, é necessário vencer muitas barreiras, como por exemplo, o número de alunos e outros problemas (Registro Escrito, professora Edilene, Cadernos de Anotações, 08/05/2018).

O curso teve muitas contribuições significativas, mas temos que levar em consideração que os estudos dos Cadernos dependem das dificuldades $e$ facilidades em aplicar tais conteúdos, tanto teórico quanto prático em salas de aulas numerosas e heterogêneas (Registro Escrito, professora Maria, Caderno de Anotações, 08/05/2108).

Nos registros das participantes foi possível identificar também, contribuições do PNAIC para o repensar suas práticas, como: ampliação do conhecimento como professoras alfabetizadoras; reflexão da prática pedagógica; troca de experiências; novas aprendizagens; material de estudo de qualidade e diferentes pontos de vista em relação ao trabalho com a disciplina de Matemática. Essas percepções foram detectadas a partir das seguintes falas:

Acrescento que uma das coisas que tenho repensado, é utilizar de contextos reais para criar situações-problema onde o aluno seja levado a resolvê-las; $e$ não apenas faça uma repetição de atividades descontextualizada (Registro professora Avany, Caderno de Anotações, 09/10/18).

O curso foi importante para que a gente refletisse sobre a prática em sala de aula e a aprendizagem obtida através do PNAIC serviu para o aprimoramento do trabalho de Matemática com os alunos (Registro professora Sandra, Caderno de Anotações, 08/05/2018).

A partir das Sessões Reflexivas, surgiram temas que permitiram confronto de informações, regularidades e padrões e, possibilitando-nos estabelecer algumas relações pertinentes. Atitudes de colaboração entre os pares, dar voz aos participantes legitimando opiniões e sugestões, tornou-se um agente participativo do processo. Esses elementos reforçam a contribuição da participação na Sessão Reflexiva e de sua significância para 
as professoras, pois contribuiu para o despertar da consciência sobre a formação docente e sobre as condições profissionais limitadas.

A percepção de valorizar o trabalho colaborativo propiciou o olhar para o rompimento do trabalho individualizado, pois ele cria possibilidades para um trabalho no qual há contribuições conjuntas para a superação de conflitos e barreiras.

O uso da Sessão Reflexiva foi significativo para as professoras, pois contribuiu para o despertar da consciência sobre a formação docente e sobre as condições profissionais limitadas. A reflexão é essencial para a construção da identidade docente e o desenvolvimento profissional, pois permite que o professor seja capaz de transformar sua prática e se constituir como sujeito autônomo que pode suscitar mudanças no contexto educacional (ALARCÃO, 1996).

É importante ressaltar que o professor não se constitui como profissional sozinho, mas em interação com outras pessoas de seu convívio escolar e de outros lugares. A reflexão é um processo coletivo (CONTRERAS, 2002). O contato com os pares durante a Sessão Reflexiva permitiu um rico compartilhamento de experiências, que levou a uma reflexão da própria prática, ampliou o olhar e levou-as a exporem suas ideias e pensamentos, de forma a permitir a percepção das implicações políticas e ideológicas de sua docência. Produzindo elos no trabalho docente, a experiência e a vivência em sala de aula como prática educativa proporciona o agir profissional dos professores.

O pensar e o refletir sobre o que se faz, principalmente se forem produzidos em contextos de desenvolvimento de trabalho docente, produzem uma série de conhecimentos sobre práticas educativas e pedagógicas.

Outras demandas também surgiram no decorrer das sessões como as necessidades formativas do professor e constataram ser falhas na área específica de Matemática. Dialogamos a respeito de possíveis causas para isso ter ocorrido, a maioria absoluta do grupo atribuiu à Educação que receberam na infância e na vida escolar a responsabilidade pelas dificuldades enfrentadas pela disciplina Matemática, alegando, também, a questão da formação inicial e superior que ensinam muito pouco essa disciplina.

A dinâmica de formação utilizada no PNAIC propiciou que os depoimentos das professoras esclarecessem concepções advindas de suas vidas acadêmicas, ao serem questionadas sobre possíveis necessidades formativas em sua vida profissional:

Eu atribuo a Educação que eu tive na infância. Foi muito falha. O professor sabia e eu tinha que aprender do jeito que ele sabia, do jeito que ele ensinava, não do jeito que eu conseguia. Entendeu, não foi respeitado o jeito que eu 
aprenderia Matemática. Do jeito que ele passava, tinha que ser feito. Era só o jeito dele que era correto. Então, eu acho que, no meu caso, eu, a gente pega raiva da Matemática. Nossa todo mundo odiava Matemática por conta disso. E no fundamental II só piora, a tendência foi só piorar. Aí já começam as humilhações pelos colegas, pelos professores No meu caso, eu acho que foi isso (Professora Edilene, Sessão Reflexiva, 22/05/2018).

Eu tenho uma péssima lembrança, porque assim, desde quando a gente começa a infância na escola, a Matemática sempre foi tratada como se fosse o "terror", "um bicho de sete cabeças". E quando eu estudei aqui na escola (citou o nome de uma escola do bairro conhecida por todas as professoras participantes), tinha uma professora, com a qual eu fiquei com nota vermelha nos três bimestres, só tinha o quarto bimestre para recuperar. Na verdade, era a sala toda, para ser bem sincera. Eu estudei o livro de trás para frente, de frente para trás para eu passar de ano. Foi muito dificil porque eu não conseguia compreender o jeito que ela ensinava. Eu queria fazer do meu jeito. Eu tinha um pouco de lentidão para entender as expressões e as equações e ela queria que a gente entendesse e aprendesse naquele ritmo, então, foi muito difícil, para a sala, para mim, foi um processo muito complicado pois a Matemática, ela é vista de um modo muito mecânico, até hoje, não tinha nenhum prazer para o educando, estar ali naquela aula, com aquele professor (Professora Sandra, Sessão Reflexiva, 22/05/2018).

Eu, por exemplo, tenho muita dificuldade de trabalhar com a parte da Geometria devido às dificuldades que eu vivi na minha Educação e também na minha formação. Eu acho que até hoje, mesmo após vários cursos e formações, isso ainda reflete negativamente nas minhas aulas. Mesmo a gente dominando o conteúdo, a gente sente insegurança para trabalhar (Professora Salete, Sessão Reflexiva, 22/05/2018).

As professoras constataram, ainda, que as facilidades e dificuldades encontradas em se trabalhar com a Matemática vêm da vida de estudante, pois consideram reproduzir modelos e se sentem inseguras quanto ao ensino deste componente curricular. Percebemos que o modelo de Educação Matemática vivenciado pelas professoras é muito forte nas suas falas, mesmo quando percebem e criticam tais modelos. Elas viveram diferentes práticas em suas vidas acadêmicas e não é nosso objetivo aqui discorrer sobre suas crenças. Mesmo porque “[...] essas crenças são construídas historicamente; daí a importância de analisar, em cursos de formação, a trajetória das professoras para identificar quais são essas crenças e como elas podem ser trabalhadas para ser rompidas e / ou transformadas", embora saibamos que "[...] não há como separar as crenças dos diferentes saberes que compõem o repertório de saberes profissionais" (NACARATO; MENGALI; PASSOS, 2009, p. 24).

O compartilhamento de experiências pedagógicas e metodológicas contribui para o desenvolvimento profissional e para o processo formativo dos professores, fato este confirmado por Tardif $(2014$, p. 11) quando alega que:

[...] o saber dos professores é o saber deles e está relacionado com a pessoa e com a identidade deles, com a sua experiência de vida e com a sua história 
profissional, com as suas relações com os alunos em sala de aula e com os outros atores escolares na escola, etc. Por isso, é necessário estudá-lo relacionando-o com esses outros elementos constitutivos do trabalho docente.

O curso PNAIC parece ter reforçado o entendimento das professoras de que "[...] o aprendiz produz o seu conhecimento, quando se envolve com as atividades pedagógicas propostas buscando o seu verdadeiro sentido (OLIVEIRA, 2009, p. 174).

$\mathrm{Na}$ maioria das vezes, é preciso analisar historicamente a trajetória de vida das pessoas, no sentido de refletir, transformar e romper com determinadas atitudes adquiridas e usadas por longos anos, advindas do modelo de ensino de Matemática por elas vivenciadas.

\section{CONSIDERAÇÕES FINAIS}

No desenvolver da pesquisa que originou este artigo, buscamos considerar as falas e os anseios das professoras ao ouvi-las e considerá-las registrando cada detalhe vivido durante o curso de formação do PNAIC-2014 para compreendermos essa formação. As vivências compartilhadas durante situações de ensino e aprendizagem em Matemática nos trouxeram um pouco das expectativas e das necessidades formativas dessas professoras.

Ao nos propor compreender como professoras que frequentaram a formação continuada do PNAIC no ano de 2014 perceberam e compreenderam essa formação, tivemos a intenção de contribuir com a Educação do município de Uberlândia. A reflexão iniciada a partir das análises das informações obtidas por meio das vozes, das escritas e das indagações das professoras participantes da nossa pesquisa, possibilitaram-nos compreender as percepções didático-pedagógicas sobre o PNAIC no olhar desse grupo de professoras. Durante nossas conversas compartilhadas, percebemos o esforço por parte delas, em ensinar Matemática de forma significativa, dinâmica e lúdica, possibilitando a compreensão dos conteúdos matemáticos atrelados às situações do cotidiano a partir dos conhecimentos dos alunos.

A formação inicial - o Curso de Magistério - e a formação superior - o Curso de Pedagogia e o Normal Superior - parecem não ter contribuído efetivamente para a superação de todas as defasagens e desconfortos seja para aprender ou para ensinar a Matemática. Para o preparo mais adequado desses professores, torna-se necessário potencializar o desenvolvimento profissional, para que aprendam Matemática e saibam ensinar Matemática, levando em consideração as especificidades da criança. O processo 
de formação de professores - inicial ou continuada - é permeado por uma multiplicidade de fatores que se interagem, cruzam-se e misturam-se.

Sendo assim, abrem-se lacunas na formação dos professores que são agravadas pelas dificuldades fundamentadas em percepções construídas historicamente sobre conceito, ensino e aprendizagem da Matemática. Percepções como conteúdo de difícil assimilação que foi transmitido por gerações passadas e pelas aulas reproduzidas por professores e que preparam outros professores para esse ofício. Ainda assim, acreditamos que a formação continuada oferecida pelo PNAIC-2014, bem como a possibilidade de retomada e de reflexão coletiva, implicaram em mudanças significativas nas práticas docentes da escola, além de oferecerem a experiência do novo, do diferente, a partir das vivências compartilhadas entre os pares, que oportunizaram um processo permanente de mudanças e de intervenções. Vale ressaltar que um atendimento diferenciado e individualizado em salas superlotadas com um único professor é um desafio.

Acreditamos, ainda, que, a participação em processos formativos, os professores são levados a pensar e a refletir sobre diferentes assuntos e, a partir deles, posicionaremse e mudarem suas formas de agir, elaborarem novos conhecimentos que contribuirão efetivamente em suas práticas pedagógicas.

Sabemos que nosso trabalho não se findou, o esforço imbricado nesta pesquisa abre um leque para várias outras. Superados os obstáculos encontrados, vimos um novo caminho a seguir e uma nova direção. Este trabalho é mais uma indicação da necessidade de pesquisas que visam a melhoria da escola pública gratuita e de qualidade.

\section{REFERÊNCIAS}

ALARCÃO, I. Reflexão crítica sobre o pensamento de D. Schön e os programas de formação de professores. In: ALARCÃO, I. (org.). Formação Reflexiva de Professores Estratégias de Supervisão. Porto: Porto, 1996.

BRASIL. Ministério da Educação - Secretaria de Educação Fundamental. Parâmetros Curriculares Nacionais: Matemática. Volume 3. Brasília: MEC/SEF, 1997.

Ministério da Educação - Secretaria de Educação Básica. Pacto Nacional pela Alfabetização na Idade Certa: formação do professor alfabetizador: Caderno de apresentação. Brasília, 2012a.

. Ministério da Educação - Secretaria de Educação Básica. Diretoria de Currículos e Educação Integral - DICEI. Coordenação Geral do Ensino Fundamental COEF. Elementos conceituais e metodológicos para definição dos direitos de 
aprendizagem e desenvolvimento do ciclo de alfabetização $\left(1^{\circ}, 2^{\circ}\right.$ e $3^{\circ}$ anos $)$ do Ensino Fundamental. Brasília: MEC, 2012b.

Ministério da Educação - Secretaria de Educação Básica. Pacto Nacional pela Alfabetização na Idade Certa: Apresentação. Brasília, 2014a.

CONTRERAS, J. A autonomia de professores. Tradução de Sandra Trabucco Valenzuela. São Paulo: Cortez, 2002.

GIL, A. C. Métodos e técnicas de pesquisa social. 6.ed. São Paulo: Atlas, 2008.

IBIAPINA, I. M. L. M. Pesquisa colaborativa: investigação, formação e produção de conhecimentos. Brasília: Liber Livro, 2008.

IMBERNÓN, F. Formação docente e profissional: formar-se para a mudança e a incerteza. 4. ed. São Paulo, Cortez Editora, 2004.

LOPES, A. R. L. V.; et al. As tramas da formação docente no contexto de um projeto: o princípio do compartilhamento. Revista Paranaense de Educação Matemática, v. 8, 2019, p. 287-309. Disponível em:

http://rpem.unespar.edu.br/index.php/rpem/article/viewFile/1830/pdf_320. Acesso em 22/11/2019.

MARCO, F. F.; MOURA, M. O. Quando ações desenvolvidas por professores em processo de formação se constituem em atividade orientadora de formação docente: alguns indicadores. In: LOPES, A. R. L. V.: ARAÚJO, E. S.; MARCO, F. F.de (Org.). Professores e futuros professores em atividades de formação. Campinas: Pontes, 2016, p.19-39.

MUNDIM, J. S. M. Modelagem Matemática nos primeiros anos do Ensino Fundamental. 2015. Dissertação (Mestrado em Educação) - Faculdade de Educação, Universidade Federal de Uberlândia, Programa de Pós-Graduação em Educação, Uberlândia, 2015.

NACARATO, A. M.; MENGALI, B. L. da S.; PASSOS, C. L. B. A Matemática nos anos iniciais do Ensino Fundamental: tecendo fios do ensinar e do aprender. Belo Horizonte: Autêntica, 2009.

OLIVEIRA, G. S. Crenças de professores dos primeiros anos do Ensino Fundamental sobre a prática pedagógica em Matemática. Tese (Doutorado em Educação). Faculdade de Educação, Universidade Federal de Uberlândia, Uberlândia. 2009.

SERRAZINA, M. L. M. Conhecimento matemático para ensinar: papel da Planificação e da reflexão na formação de professores. Revista Eletrônica de Educação. São Paulo: UFSCAR, v.6, n. 1, 2012, p.266-283. Disponível em: http://www.reveduc.ufscar.br/index.php/reveduc/article/view/355. Acesso em 03/01/2019. 
SIMÃO, L. E. de S. A. Percepções de um grupo de professores que ensinam Matemática sobre o Pacto Nacional pela Alfabetização na Idade Certa (PNAIC).

Dissertação (Mestrado em Educação). Faculdade de Educação, Universidade Federal de Uberlândia, Uberlândia. 2019.

TARDIF, M. Saberes docentes e formação profissional. 17. Ed. Petrópolis, RJ:

Vozes, 2014.

Submetido em 30 de dezembro de 2019. Aprovado em 03 de junho de 2020. 